\title{
Protective Actions of Globular and Full-Length Adiponectin on Human Endothelial Cells: Novel Insights into Adiponectin-Induced Angiogenesis
}

\author{
Raghu Adya $^{a}$ Bee K. Tan ${ }^{a, b}$ Jing Chen ${ }^{a}$ Harpal S. Randeva ${ }^{a}$ \\ a Division of Metabolic and Vascular Health, Warwick Medical School, University of Warwick, Coventry, and \\ ${ }^{b}$ Department of Reproductive Medicine and Surgery, Addenbrooke's Hospital, Cambridge University Hospitals \\ NHS Foundation Trust, Cambridge, UK
}

\section{Key Words}

Adipokine $\cdot$ Adiponectin $\cdot$ Angiogenesis $\cdot$ Atherosclerosis

\begin{abstract}
Background/Aims: Adiponectin levels are decreased in diabetes and atherosclerosis. Coexisting hyperglycaemia and systemic inflammation predisposes to dysregulated angiogenesis and vascular disease. We investigated the effect of globular adiponectin ( $\mathrm{gAd}$ ) and full-length adiponectin (fAd) on angiogenesis and pro-angiogenic molecules, i.e. matrix metalloproteinase (MMP)-2, MMP-9 and vascular endothelial growth factor (VEGF), in human microvascular endothelial cells (HMEC-1). Methods: Angiogenesis was assessed by studying capillary tube formation in HMEC-1 on growth factor-reduced Matrigel. Endothelial cell migration assay was performed in a modified Boyden chamber. $\boldsymbol{R e}$ sults: Endothelial cell proliferation, in vitro migration and angiogenesis were significantly increased by gAd (mediated by AdipoR1, AMPK-Akt pathways), and gAd significantly increased MMP-2, MMP-9 and VEGF expression levels. The effect of gAd on VEGF appears to be mediated by AdipoR1, whilst the effect of gAd on MMP-2 and MMP-9 appears to be mediated by AdipoR1 and AdipoR2. Only endothelial cell
\end{abstract}

proliferation was significantly increased by fAd in human microvascular endothelial cells and appears to be mediated by AdipoR2. No significant effects on MMP-2, MMP-9 and VEGF were observed. Importantly, gAd decreased glucose and Creactive protein-induced angiogenesis with a concomitant reduction in MMP-2, MMP-9 and VEGF in HMEC-1 cells. Conclusion: We report novel insights into the mechanisms of adiponectin on angiogenesis. Copyright $\odot 2012$ S. Karger AG, Basel

\section{Introduction}

Obesity, in particular visceral adiposity, has reached pandemic proportions and is associated with serious cardiometabolic sequelae including insulin resistance, hyperinsulinaemia, type 2 diabetes mellitus, dyslipidaemia, hypertension and vascular disease - all features of the metabolic syndrome [1]. In relation to this, the metabolic syndrome is associated with excessive accumulation of central body fat, i.e. visceral obesity. As well as its role in energy storage, adipose tissue produces several hormones and cytokines termed 'adipokines' that have widespread effects on carbohydrate and lipid metabolism. They ap-

\section{KARGER}

Fax +4161306 1234

E-Mail karger@karger.ch

www.karger.com (c) 2012 S. Karger AG, Basel

$1018-1172 / 12 / 0496-0534 \$ 38.00 / 0$

Accessible online at:

www.karger.com/jvr
Dr. Harpal S. Randeva

Division of Metabolic and Vascular Health

Warwick Medical School, University of Warwick

Coventry CV4 7AL (UK)

Tel. +44 2476572 552, E-Mail Harpal.Randeva@ warwick.ac.uk 
pear to play an important role in the pathogenesis of insulin resistance, type 2 diabetes mellitus and vascular disease [2].

Adiponectin is an adipokine that circulates at high levels, with lower levels noted in obesity, type 2 diabetes mellitus and vascular disease [3]. Adiponectin exerts metabolic and vascular protection through its insulin sensitizing, anti-inflammatory and anti-atherogenic effects [3]. In relation to this, circulating adiponectin levels have recently been shown to be predictive of myocardial infarction in patients with chest pain [4]. Adiponectin is present in human plasma as different multimers, i.e. high molecular weight (HMW), mid-molecular weight (MMW) and low molecular weight (LMW) adiponectin, and low circulating HMW adiponectin levels have been associated with obesity, diabetes and vascular disease [5-7]. Additionally, in non-diabetic men, multimeric forms of adiponectin rather than total adiponectin seem to be associated with myocardial infarction [8].

Adiponectin exists in human plasma mainly as fulllength adiponectin (fAd). A smaller, globular fragment, i.e. globular adiponectin ( $\mathrm{gAd}$ ), is also present in human plasma [9]. It has been suggested that gAd is formed from proteolytic cleavage by leukocyte elastase secreted by activated neutrophils or monocytes [9]. Controversy has arisen with regards to adiponectin and vascular inflammation [10-12]. Hattori et al. [11, 12] reported that gAd activates nuclear factor- $\kappa \mathrm{B}$, suggesting a pro-inflammatory effect. This notion has been challenged by other leading adiponectin research groups [10]. The relationship between inflammation, insulin resistance and vascular disease is well established [13].

Adipokines play important roles in the induction of dysregulated angiogenesis and atherogenesis $[14,15]$. As part of an inflammatory/angiogenic response, the extracellular matrix is remodelled by proteolytic enzymes termed as matrix metalloproteinases (MMPs), of which the gelatinases (MMP-2 and MMP-9) play a vital role [16]. Increased MMP activity has been linked to atherosclerosis and vascular disease [17]. MMPs are upregulated by a plethora of hormones, cytokines and growth factors, including a potent vascular mitogen, vascular endothelial growth factor (VEGF) [18].

With the aforementioned in mind, we undertook this study to investigate the effect of gAd and fAd on endothelial cell proliferation as well as in vitro migration and angiogenesis with respect to endothelial angiogenic factors, specifically, MMP-2, MMP-9 and VEGF. Furthermore, we sought to elucidate the involvement of the adiponectin receptors, i.e. adiponectin receptor 1 (AdipoR1) and adi- ponectin receptor 2 (AdipoR2). More importantly, given the connection between the coexistence of hyperglycaemia and systemic inflammation with vascular disease in pathological states such as diabetes mellitus, we also studied the interaction between glucose and C-reactive protein (CRP), respectively, with gAd and fAd [19, 20]. Finally, since AMP-activated protein kinase (AMPK), a stress-activated protein kinase, and Akt have been implicated as critical mediators of adiponectin-induced angiogenesis in both normoxic and ischemic tissues, we examined the role of these signalling pathways in gAd-induced endothelial angiogenesis [21].

\section{Materials and Methods}

\section{Chemicals and Reagents}

Human recombinant peptides fAd, gAd and antibodies AdipoR1 and AdipoR2 were obtained from Phoenix Pharmaceuticals (Burlingame, Calif., USA). PI3K/Akt inhibitor LY 294002, AMPK inhibitor compound $\mathrm{C}$ and human recombinant VEGF came from Calbiochem (Lutterworth, UK). MMP-2, MMP-9 and VEGF antibodies came from Abcam (Cambridge, UK).

\section{Cell Culture}

Human microvascular endothelial cells (HMEC-1) were obtained from the Centre for Disease Control (Atlanta, Ga., USA). HMEC-1 cells were cultured in MCDB medium (Sigma-Aldrich, Gillingham, UK) supplemented with 10\% Fetal Calf Serum (FCS; Sigma-Aldrich), $100 \mathrm{IU} / \mathrm{ml}$ penicillin (Sigma-Aldrich), $100 \mu \mathrm{g} / \mathrm{ml}$ streptomycin (Sigma-Aldrich), $5 \mathrm{ml}$ of $200 \mathrm{mM} \mathrm{L}$-glutamine/500 $\mathrm{ml}$ of media, hydrocortisone $2 \mu \mathrm{M}$, epidermal growth factor $2 \mathrm{ng} /$ $\mathrm{ml}$ (Invitrogen, Paisley, UK) at $37^{\circ} \mathrm{C}$ in $5 \% \mathrm{CO}_{2} / 95 \%$ air. Prior to each experiment, cells were fed with MCDB with addition of $1 \%$ FCS overnight.

HMEC-1 cells were pre-incubated with or without AdipoR1 $(10 \mu \mathrm{g} / \mathrm{ml})$ or AdipoR2 $(10 \mu \mathrm{g} / \mathrm{ml})$ antibodies, respectively, for $1 \mathrm{~h}$ followed by treatment with or without fAd $(0-3 \mu \mathrm{g} / \mathrm{ml})$ or $\mathrm{gAd}$ (0-3 $\mu \mathrm{g} / \mathrm{ml}$ ) for 4-48 h (quantitative RT-PCR - mRNA expression) or for $24 \mathrm{~h}$ (western blotting - protein production). VEGF $(10 \mathrm{ng} / \mathrm{ml})$ served as positive control.

\section{Cell Proliferation Assay}

Cell proliferation was assessed using CellTiter 96 Aqueous One Solution Cell Proliferation Assay (MTS) kit (Promega, Southampton, UK) according to the manufacturer's protocol. HMEC-1 cells were pre-incubated with or without AdipoR1 $(10 \mu \mathrm{g} / \mathrm{ml})$ or AdipoR2 $(10 \mu \mathrm{g} / \mathrm{ml})$ antibodies or compound $\mathrm{C}(20 \mu \mathrm{M})$ or LY294002 $(10 \mu \mathrm{M})$ or glucose $(15 \mathrm{mM})$ or CRP $(1 \mu \mathrm{g} / \mathrm{ml})$ for $1 \mathrm{~h}$, followed by treatment with or without fAd $(0-3 \mu \mathrm{g} / \mathrm{ml})$ or $\mathrm{gAd}$ $(0-3 \mu \mathrm{g} / \mathrm{ml})$ for $4-48 \mathrm{~h}$. VEGF $(10 \mathrm{ng} / \mathrm{ml})$ served as positive control. Prior to each experiment, cells were fed with MCDB with addition of $1 \%$ FCS overnight. Following treatments, MTS reagent $(20 \mu \mathrm{l})$ was added to $100 \mu \mathrm{l}$ of culture media in each well. The absorbance was recorded by an ELISA reader (EL800; Bio-Tek Instruments Inc., Winooski, Vt., USA) at $490 \mathrm{~nm}$. 
In vitro Angiogenesis Assay

Angiogenesis was assessed by studying the formation of capillary tube-like structures by culturing HMEC-1 cells on growth factor-reduced Matrigel (BD Biosciences, San Jose, Calif., USA). Matrigel was coated onto 96-well culture plates as per the manufacturer's instructions. HMEC-1 cells (at a seeding density of $10^{5}$ cells/well) were pre-incubated with or without AdipoR1 $(10 \mu \mathrm{g} /$ $\mathrm{ml})$ or AdipoR2 $(10 \mu \mathrm{g} / \mathrm{ml})$ antibodies or compound C $(20 \mu \mathrm{M})$ or LY294002 $(10 \mu \mathrm{M})$ or glucose $(15 \mathrm{mM})$ or CRP $(1 \mu \mathrm{g} / \mathrm{ml})$ for $1 \mathrm{~h}$, followed by treatment with or without fAd $(0-3 \mu \mathrm{g} / \mathrm{ml})$ or gAd $(0-3 \mu \mathrm{g} / \mathrm{ml})$ for $4-48 \mathrm{~h}$. VEGF $(10 \mathrm{ng} / \mathrm{ml})$ served as positive control. Trypsinized HMEC-1 cells were then seeded onto the Matrigel-coated plates at a density of $4-5 \times 10^{3} /$ well in fresh media and incubated at $37^{\circ} \mathrm{C}$. Capillary tube formation images were captured with a digital microscope camera system (Olympus, Tokyo, Japan). Image Pro Plus software was used to quantify tube length formation; the lengths of tubes in 3-4 randomly selected fields in each of the wells were measured.

\section{In vitro Migration Assay}

Endothelial cell migration assay was performed in a modified Boyden chamber using a protocol obtained from BD BioCoat Angiogenesis System (BD Biosciences). Endothelial cells were trypsinised; a cell suspension of $4 \times 10^{5}$ cells $/ \mathrm{ml}$ was prepared, $250 \mu \mathrm{l}$ of which was added to each trans-well insert. $750 \mu$ l of starvation media was added to the lower chamber and incubated overnight. Following this, the cells were labelled by incubating with Hank's Balanced Salt Solution medium (Sigma-Aldrich) containing $4 \mu \mathrm{g} /$ $\mathrm{ml}$ Calcein-AM (BD Biosciences) for $90 \mathrm{~min}$. HMEC-1 cells were pre-incubated with or without AdipoR1 $(10 \mu \mathrm{g} / \mathrm{ml})$ or AdipoR2 $(10 \mu \mathrm{g} / \mathrm{ml})$ antibodies or compound C $(20 \mu \mathrm{M})$ or LY294002 (10 $\mu \mathrm{M})$ or glucose $(15 \mathrm{mM})$ or CRP $(1 \mu \mathrm{g} / \mathrm{ml})$ for $1 \mathrm{~h}$, followed by treatment with or without fAd $(0-3 \mu \mathrm{g} / \mathrm{ml})$ or gAd $(0-3 \mu \mathrm{g} / \mathrm{ml})$ for 4-48 h. VEGF $(10 \mathrm{ng} / \mathrm{ml})$ served as positive control. Cells were fixed with $2 \%$ formaldehyde. The fluorescence of migrated cells was read in a fluorescence plate reader with bottom reading capabilities at excitation/emission wavelengths of 494/517 nm. Only those labelled cells that had migrated through the pores of the membrane would be detected.

\section{Total RNA Extraction and cDNA Synthesis}

Total RNA was extracted from HMEC-1 cells using Qiagen RNeasy Mini Kit according to the manufacturer's guidelines (Qiagen, Crawley, UK). The purity of the extracted RNA was measured by a NanoDrop spectrophotometer. A set concentration of RNA was reverse transcribed into cDNA by using M-MuLV Reverse Transcriptase (Fermentas, York, UK) and random hexamers (Promega, Southampton, UK) as primers.

\section{Reverse Transcriptase Polymerase Chain Reaction}

Quantitative PCR of MMP-2, MMP-9 and VEGF were performed on a Roche Light Cycler ${ }^{\mathrm{TM}}$ system (Roche Molecular Biochemicals, Mannheim, Germany). PCR reactions were carried out in a reaction mixture consisting of $5.0 \mu \mathrm{l}$ reaction buffer and $2.0 \mathrm{mM} \mathrm{MgCl}_{2}$ (Biogene, Kimbolton, UK), $1.0 \mu \mathrm{l}$ of each primer $(10 \mathrm{nM}), 2.5 \mu \mathrm{l}$ of cDNA and $0.5 \mu \mathrm{l}$ of Light Cycler DNA Master SYBR ${ }^{\circledR}$ Green I (Roche Molecular Biochemicals). Protocol conditions consisted of denaturation of $95^{\circ} \mathrm{C}$ for $15 \mathrm{~s}$, followed by 40 cycles of $94^{\circ} \mathrm{C}$ for $1 \mathrm{~s}, 60^{\circ} \mathrm{C}$ for $5 \mathrm{~s}$ and $72^{\circ} \mathrm{C}$ for $12 \mathrm{~s}$, followed by melting curve analysis. For analysis, quantitative amounts of genes of interest were standardised against the housekeeping gene GAPDH. The RNA levels were expressed as a ratio, using the 'delta-delta method' for comparing relative expression results between treatments in real-time PCR [22]. The sequences of the sense and anti-sense primers used were: MMP-2 (179 bp) 5'-TGGCAAGTACGGCTTCTGTC-3' and $5^{\prime}$-TTCTTGTCGCGGTCGTAGTC-3'; MMP-9 (200 bp) 5'-TGCGCTACCACCTCGAACTT$3^{\prime}$ and $5^{\prime}$-GATGCCATTGACGTCGTCCT-3'; VEGF (196 bp) 5'CGGCGAAGAGAAGAGACACA-3' and 5'-GGAGGAAGGTCAACCACTCA-3'; GAPDH (185 bp) 5'-GAGTCAACGGATTTGGTC GT-3' and 5'-GACAAGCTTCCCGTTCTCAG-3' [23]. 10 $\mu l$ of the reaction mixture(s) were subsequently electrophoresed on a $1 \%$ agarose gel and visualised by ethidium bromide, using a $1 \mathrm{~kb}$ DNA ladder (Invitrogen) in order to estimate the band sizes. As a negative control for all the reactions, preparations lacking RNA or reverse transcriptase were used in place of the cDNA. RNAs were assayed from three independent biological replicates.

Sequence Analysis

The PCR products from all samples were purified from the $1 \%$ agarose gel using the QIAquick Gel Extraction Kit (Qiagen). PCR products were then sequenced in an automated DNA sequences, and the sequence data were analysed using Blast nucleic acid database searches from the National Centre for Biotechnology Information, confirming the identity of our products.

\section{Gelatin Zymography}

The conditioned media of the in vitro angiogenesis assay was collected and centrifuged to remove cell debris. The gelatinolytic activities of secreted MMP-2 and MMP-9 in conditioned media were measured by gelatin zymography. $10 \mu \mathrm{l}$ of conditioned media was mixed with $10 \mu \mathrm{l}$ zymography sample buffer and subjected to SDS-polyacrylamide gel electrophoresis (10\% resolving gel) containing $1 \mathrm{mg} / \mathrm{ml}$ of gelatin (Sigma-Aldrich) under nonreducing conditions. Gels were washed twice for $30 \mathrm{~min}$ with renaturation buffer $(2.5 \%$ Triton X-100) at room temperature and then incubated overnight in incubation buffer $(50 \mathrm{~mm}$ Tris- $\mathrm{HCl}$ $\mathrm{pH} 7.5,200 \mathrm{mM} \mathrm{NaCl}, 10 \mathrm{mM} \mathrm{CaCl}_{2}, 1 \mu \mathrm{M} \mathrm{ZnCl}_{2}$ ) at $37^{\circ} \mathrm{C}$. Characterization of MMP activity was determined by inhibition with EDTA $(10 \mathrm{~mm}), 1.10$ phenantroline and $p$-aminophenylmercuric acetate (data not shown). Following incubation, gels were stained for $1 \mathrm{~h}(0.25 \%$ Coomassie Brilliant Blue R-250 in 45\% methanol and $10 \%$ acetic acid) and destained in the same buffer without Coomassie. White bands against a blue background were observed following destaining demonstrating the gelatinolytic activities of MMP-2 and MMP-9, respectively. The band intensities were measured using Gel-Pro image analysis (Gel-Pro 4.5; Media Cybernetics, Bethesda, Md., USA). Additionally, standard curves were generated for both MMP-2 and MMP-9 to enable the quantification [24]. All data presented are within the linear range of the standard curve.

\section{Endotoxin Measurements}

Endotoxin contamination of the reagents (fAd, gAd, AdipoR1 and AdipoR2) used was assessed by using a kinetic chromogenic test based on the limulus amebocyte lysate assay, as per the manufacturers protocol (Kinetic-QCL; BioWhittaker, Walkersville, Md., USA; online suppl. material; for all online suppl. material, see www.karger.com/doi/10.1159/000338279). 


\section{Statistics}

Data were analysed by Mann-Whitney $U$ test or Friedman ANOVA (post hoc analysis: Dunn's test) according to the number of groups compared. All statistical analyses were performed using SPSS version 18.0 (SPSS Inc., Chicago, Ill., USA). $\mathrm{p}<0.05$ was considered significant.

\section{Results}

\section{Effects of fAd and gAd on Human Endothelial Cell Proliferation}

Concentration and time-dependent experiments revealed that the optimum concentration and time point for fAd and gAd on HMEC-1 cell proliferation were $3 \mu \mathrm{g} /$ $\mathrm{ml}$ and $24 \mathrm{~h}$, respectively (online suppl. fig. 1). fAd ( $3 \mu \mathrm{g} /$ $\mathrm{ml})$ and $\mathrm{gAd}(3 \mu \mathrm{g} / \mathrm{ml})$ significantly increased HMEC-1 cell proliferation at $24 \mathrm{~h}$ (fig. 1a), the effects of gAd were inhibited when HMEC-1 cells were pre-incubated with AdipoR1 (10 $\mu \mathrm{g} / \mathrm{ml})$ antibody (fig. 1a) and the effects fAd were inhibited when HMEC-1 cells were pre-incubated with AdipoR2 $(10 \mu \mathrm{g} / \mathrm{ml})$ antibody (fig. 1a). Furthermore, the effects of gAd were inhibited when HMEC-1

Fig. 1. a HMECs were pre-incubated with or without AdipoR1 $(10 \mu \mathrm{g} / \mathrm{ml})$ or AdipoR2 $(10 \mu \mathrm{g} / \mathrm{ml})$ antibodies or compound C (20 $\mu \mathrm{M})$ or LY294002 $(10 \mu \mathrm{M})$ for $1 \mathrm{~h}$ followed by treatment with or without gAd $(3 \mu \mathrm{g} / \mathrm{ml})$ or fAd $(3 \mu \mathrm{g} / \mathrm{ml})$ or VEGF $(10 \mathrm{ng} / \mathrm{ml}$; positive control) for $24 \mathrm{~h}$ and assessed by MTS proliferation assay. Results were expressed as the percentage of cells in relation to basal (untreated) and represent the mean of triplicates. ${ }^{* *} \mathrm{p}<$ $0.001,{ }^{* *} \mathrm{p}<0.01$ vs. basal; \# $\mathrm{p}<0.05$ vs. gAd only treated; $+\mathrm{p}<$ 0.05 vs. gAd only treated; NS = non-significant vs. either gAd or fAd; $n=6 / g r o u p$. $\mathbf{b}$ HMECs were pre-incubated with or without AdipoR1 $(10 \mu \mathrm{g} / \mathrm{ml})$ or AdipoR2 $(10 \mu \mathrm{g} / \mathrm{ml})$ antibodies or compound C $(20 \mu \mathrm{M})$ or LY294002 $(10 \mu \mathrm{M})$ for $1 \mathrm{~h}$ followed by treatment with or without gAd $(3 \mu \mathrm{g} / \mathrm{ml})$ or fAd $(3 \mu \mathrm{g} / \mathrm{ml})$ or VEGF (10 ng/ml; positive control) for $24 \mathrm{~h}$. Migrated cells were quantified using a fluorescent plate reader. The migrated cells were expressed as the ratio of the fluorescence compared with the control. Results are means \pm SE of six independent experiments. ${ }^{* * *} \mathrm{p}<0.001 ; \# \mathrm{p}<0.05$ vs. gAd only treated; NS = non-significant vs. either gAd or fAd; $n=6 /$ group. c Capillary tube formation assay. HMECs were pre-incubated with or without AdipoR1 $(10 \mu \mathrm{g} / \mathrm{ml})$ or AdipoR2 $(10 \mu \mathrm{g} / \mathrm{ml})$ antibodies or compound C (20 $\mu \mathrm{M})$ or LY294002 $(10 \mu \mathrm{M})$ for $1 \mathrm{~h}$ followed by treatment with or without gAd $(3 \mu \mathrm{g} / \mathrm{ml})$ or fAd $(3 \mu \mathrm{g} / \mathrm{ml})$ or VEGF $(10 \mathrm{ng} / \mathrm{ml}$; positive control) for $24 \mathrm{~h}$. The total length of capillary-like tubes was measured and normalised with controls. The values represented are relative to basal. ${ }^{* *} \mathrm{p}<0.001 ; \# \mathrm{p}<0.01 ; \mathrm{NS}=$ nonsignificant; $n=6 / g r o u p$. Experiments were performed in triplicates.

Globular Adiponectin and Endothelial Angiogenesis
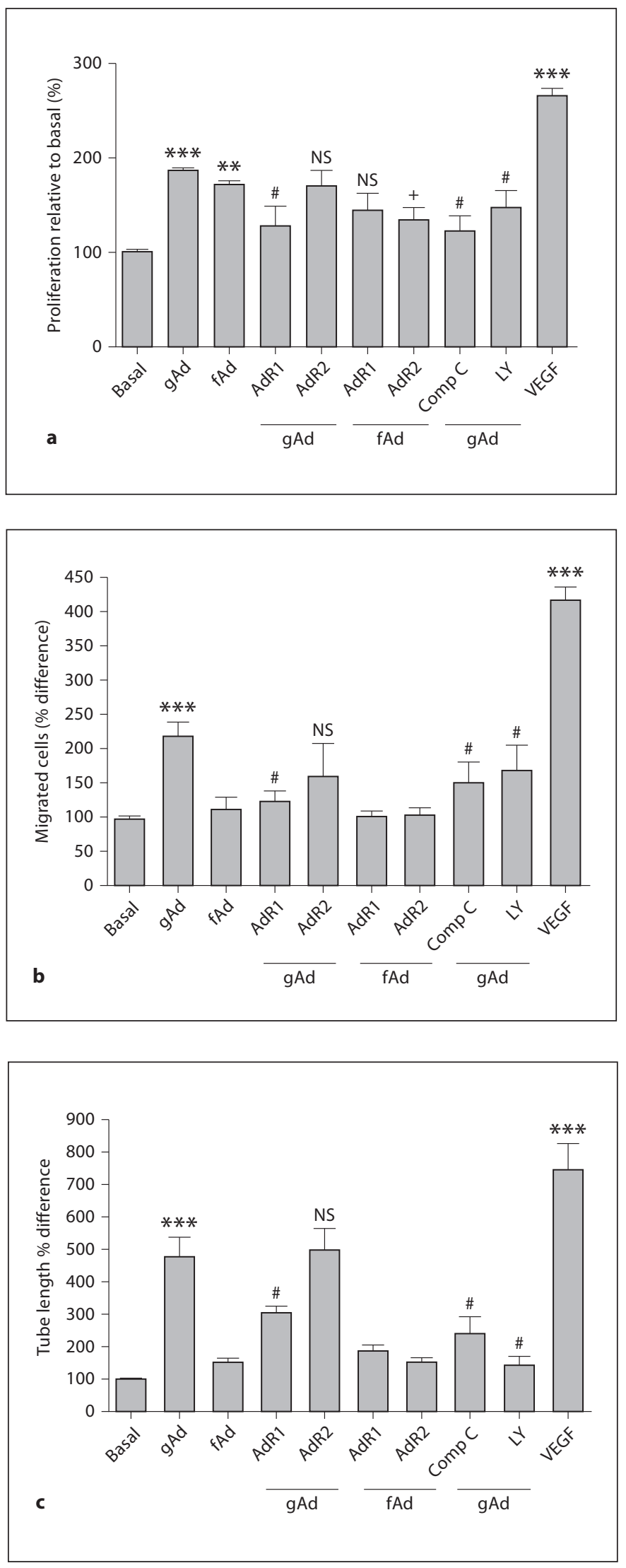

J Vasc Res 2012;49:534-543 

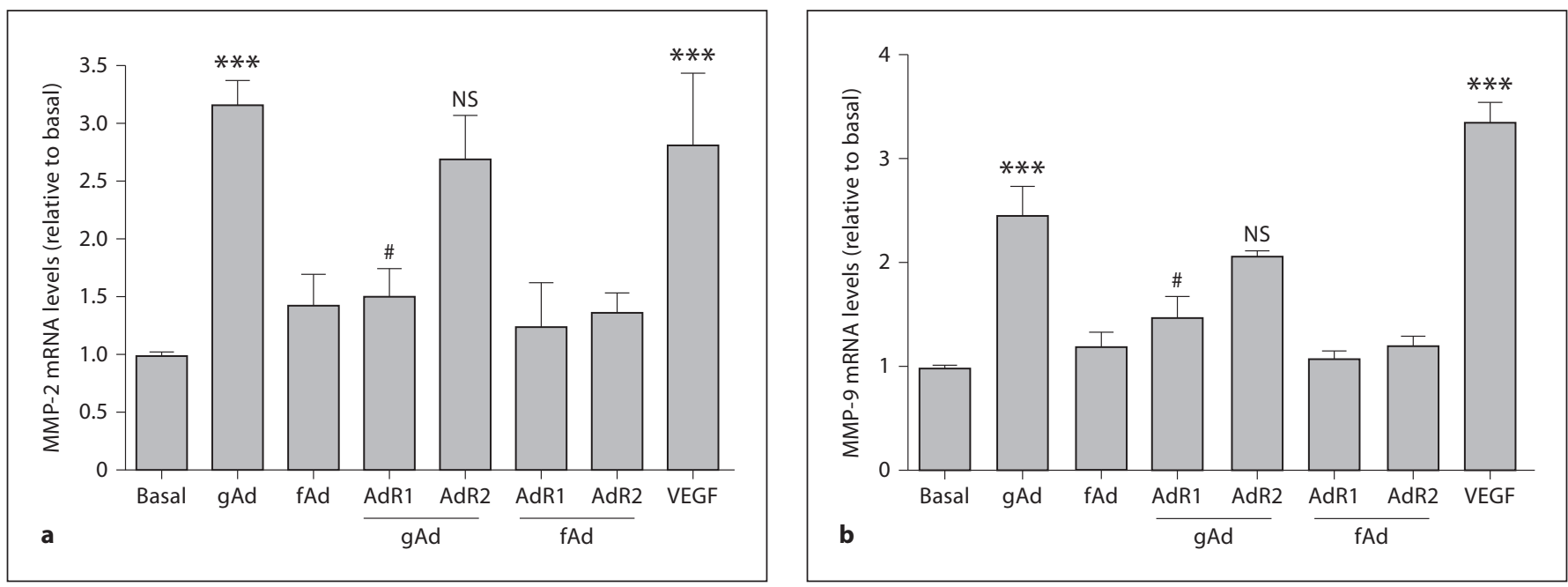

Fig. 2. HMECs were pre-incubated with or without AdipoR1 (10 $\mu \mathrm{g} / \mathrm{ml})$ or AdipoR2 $(10 \mu \mathrm{g} / \mathrm{ml})$ antibodies for $1 \mathrm{~h}$ followed by treatment with or without gAd $(3 \mu \mathrm{g} / \mathrm{ml})$ or fAd $(3 \mu \mathrm{g} / \mathrm{ml})$ or VEGF (10 ng/ml) for $4 \mathrm{~h}$. mRNA levels of MMP-2 (a), MMP-9 (b) and VEGF (c) were analysed by real-time PCR relative to GAPDH. The values represented are relative to basal. ${ }^{* *} \mathrm{p}<0.001 ; \# \mathrm{p}<$ 0.001 ; NS = non-significant; $n=6 /$ group. Experiments were performed in triplicates.

cells were pre-incubated with an AMPK inhibitor (compound C, $20 \mu \mathrm{M}$ ) and PI3k/Akt inhibitor (LY294002, 10 $\mu \mathrm{M})$, respectively (fig. 1a).

\section{Effects offAd and gAd on in vitro Migration and Angiogenesis}

Concentration and time-dependent experiments revealed that the optimum concentration and time point for gAd on in vitro migration and angiogenesis was $3 \mu \mathrm{g} /$ $\mathrm{ml}$ and $24 \mathrm{~h}$, respectively. There were no significant differences with respect to fAd (online suppl. fig. 1b, c). gAd $(3 \mu \mathrm{g} / \mathrm{ml})$ significantly increased in vitro migration and angiogenesis at $24 \mathrm{~h}$ (fig. $1 \mathrm{~b}, \mathrm{c}$ ); these effects of gAd were inhibited when HMEC-1 cells were pre-incubated with AdipoR1 antibody (fig. 1b, c). Additionally, the migratory and angiogenic effects of gAD were inhibited when HMEC-1 cells were pre-incubated with an AMPK inhib-

itor (compound C, $20 \mu \mathrm{M}$ ) and PI3k/Akt inhibitor (LY294002, $10 \mu \mathrm{M}$ ), respectively (fig. 1b, c).

Effects of fAd and gAd on MMP-2, MMP-9 and VEGF mRNA Expression Levels in Human Endothelial Cells

Concentration and time-dependent experiments revealed that the optimum concentration and time point for gAd on MMP-2, MMP-9 and VEGF mRNA expression in HMEC-1 cells was $3 \mu \mathrm{g} / \mathrm{ml}$ and $24 \mathrm{~h}$, respectively. There were no significant differences with respect to fAd (data not shown). gAd $(3 \mu \mathrm{g} / \mathrm{ml})$ significantly increased MMP-2 mRNA expression in HMEC-1 cells at $24 \mathrm{~h}$ (fig. 2a); these effects of gAd were inhibited when HMEC1 cells were pre-incubated with AdipoR1 $(10 \mu \mathrm{g} / \mathrm{ml})$ antibody (fig. 2a). gAd ( $3 \mu \mathrm{g} / \mathrm{ml})$ significantly increased MMP-9 mRNA expression levels in HMEC-1 cells at $24 \mathrm{~h}$ (fig. 2b) and the effects of gAd on MMP-9 mRNA 

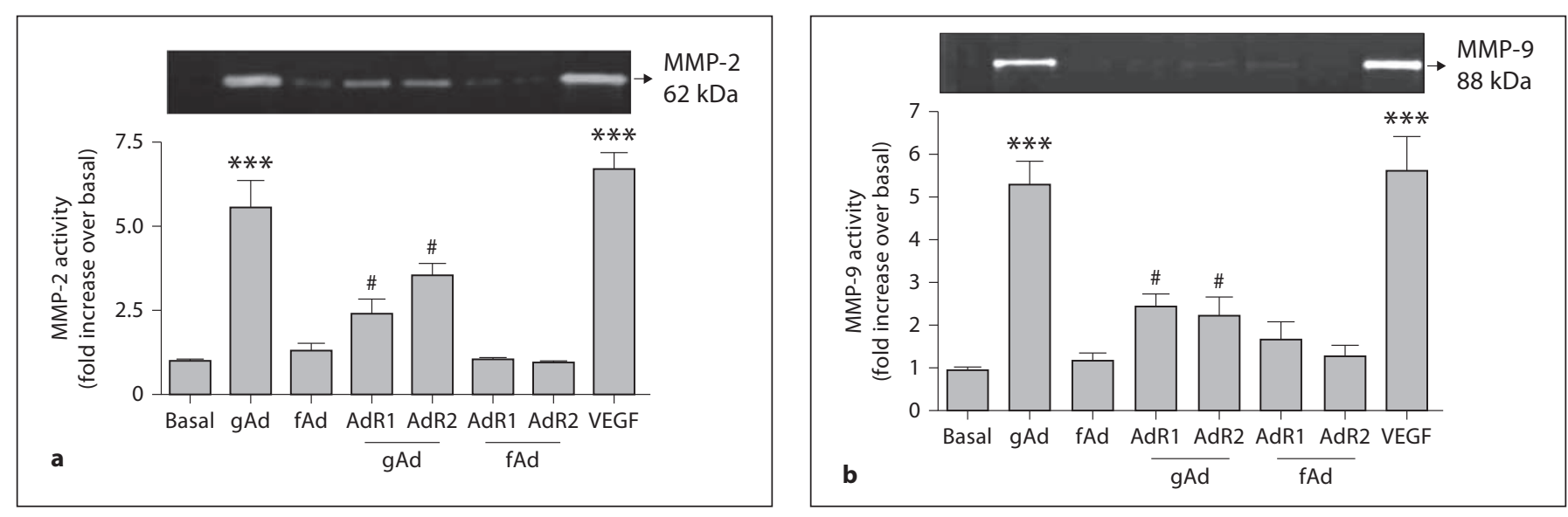

Fig. 3. a, b Representative zymograms and densitometric analysis of MMP-2 and MMP-9 protein activity in conditioned media after $24 \mathrm{~h} .{ }^{* * *} \mathrm{p}<0.001 ; \# \mathrm{p}<0.001 ; \mathrm{n}=6$ /group. Experiments were performed in triplicates.

expression were inhibited when HMEC-1 cells were preincubated with AdipoR1 (10 $\mu \mathrm{g} / \mathrm{ml})$ antibody (fig. 2b). gAd $(3 \mu \mathrm{g} / \mathrm{ml})$ significantly increased VEGF mRNA expression in HMEC-1 cells at $24 \mathrm{~h}$ (fig. $2 \mathrm{c}$ ) and these effects of gAd were inhibited when HMEC-1 cells were pre-incubated with AdipoR1 (10 $\mu \mathrm{g} / \mathrm{ml})$ antibody (fig. 2c).

\section{Effects of fAd and gAd on MMP-2 and MMP-9}

Activation in Human Endothelial Cells

Concentration and time-dependent experiments revealed that the optimum concentration and time point for gAd on MMP-2 and MMP-9 activation in HMEC-1 cells was $3 \mu \mathrm{g} / \mathrm{ml}$ and $24 \mathrm{~h}$, respectively. There were no significant differences with respect to fAd (data not shown). gAd (3 $\mu \mathrm{g} / \mathrm{ml})$ significantly increased MMP-2 and MMP-9 activation in HMEC-1 cells at $24 \mathrm{~h}$ (fig. 3a, b); these effects of gAd were inhibited when HMEC-1 cells were pre-incubated with either AdipoR1 $(10 \mu \mathrm{g} / \mathrm{ml})$ or AdipoR2 (10 $\mu \mathrm{g} / \mathrm{ml})$ antibody (fig. 3a, b).

\section{Effects of Pre-Incubating fAd and gAd on Glucose and CRP-Induced Angiogenesis in Human Endothelial Cells}

As mentioned previously, given the well-established link between the coexistence of hyperglycaemia and systemic inflammation with vascular disease in pathological states such as diabetes mellitus, we investigated the interaction between gAd/fAd with glucose and CRP-induced angiogenesis. Glucose (15 mM) and CRP $(1 \mu \mathrm{g} / \mathrm{ml})$ significantly increased HMEC-1 cell proliferation at $24 \mathrm{~h}$ (fig. 4a); the effects of glucose and CRP were inhibited when HMEC-1 cells were pre-incubated with either gAd
( $3 \mu \mathrm{g} / \mathrm{ml})$ or fAd $(3 \mu \mathrm{g} / \mathrm{ml})$, respectively (fig. 4a). Glucose $(15 \mathrm{mM})$ and CRP $(1 \mu \mathrm{g} / \mathrm{ml})$ significantly increased in vitro migration and angiogenesis at $24 \mathrm{~h}$ (fig. $4 \mathrm{~b}, \mathrm{c}$ ) and the effects of glucose and CRP were inhibited when HMEC-1 cells were pre-incubated with either gAd $(3 \mu \mathrm{g} / \mathrm{ml})$ or fAd $(3 \mu \mathrm{g} / \mathrm{ml})$, respectively (fig. $4 \mathrm{a})$. Glucose $(15 \mathrm{mM})$ and CRP $(1 \mu \mathrm{g} / \mathrm{ml})$ significantly increased MMP-2 and MMP9 mRNA expression and protein production, respectively, in HMEC-1 cells at $24 \mathrm{~h}$ (data not shown). The effects of glucose and CRP were inhibited when HMEC-1 cells were pre-incubated with gAd ( $3 \mu \mathrm{g} / \mathrm{ml}$; data not shown). Glucose $(15 \mathrm{mM})$ and CRP $(1 \mu \mathrm{g} / \mathrm{ml})$ significantly increased MMP-2 and MMP-9 activation in HMEC-1 cells at $24 \mathrm{~h}$ (fig. 5a, b), and the effects of glucose and CRP were inhibited when HMEC-1 cells were pre-incubated with either gAd $(3 \mu \mathrm{g} / \mathrm{ml})$ or fAd $(3 \mu \mathrm{g} / \mathrm{ml})$, respectively (fig. 5a, b).

\section{Discussion}

Dysfunctional angiogenesis is implicated in pathological states such as diabetes mellitus and vascular disease. MMPs and VEGF play important roles in this respect [18]. In spite of significant advances in therapeutic angiogenesis, the treatment of vascular diseases remains a challenge to medicine [25]. Opposing treatment strategies are needed to treat vascular diseases with differing pathophysiology [25]. Although inhibition of endogenous growth factors appears advantageous in certain ophthalmic conditions, such as atherosclerotic plaques, etc. the reverse is required in inducing angiogenesis for 

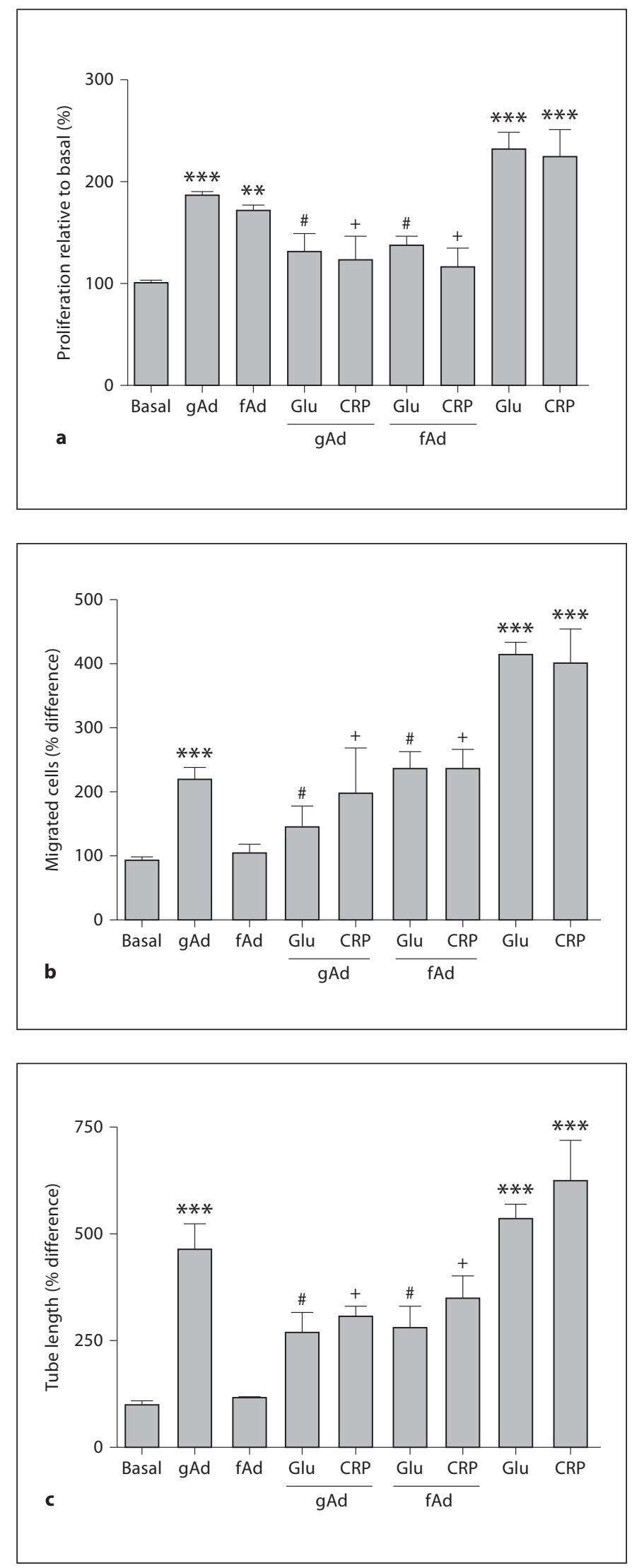

improving macrovascular insufficiency, for example in peripheral limb ischaemia [25]. Thus, the study of MMPs, VEGF and novel regulators of angiogenesis in this respect would be of paramount importance.

Ouchi et al. [21] had reported that mouse fAd stimulates in vitro migration and angiogenesis, and suggested that this effect may be beneficial in line with the report by Shibata et al. [26] who demonstrated that adiponectin promotes ischaemia-mediated revascularization in adiponectin-knockout mice. Conversely, Brakenhielm et al. [27] have reported that adiponectin had potent anti-angiogenic effects. We would like to compare and contrast as well as discuss our findings in relation to these references. With respect to Ouchi et al. [21], they described the pro-angiogenic effects of fAd in human macrovascular endothelial cells, utilising supra-physiological concentrations of $30 \mu \mathrm{g} / \mathrm{ml}$ with an optimal time point of $24 \mathrm{~h}$ for their experiments. On the other hand, Shibata et al. [26] performed experiments by injecting mice with fAd, demonstrating in vivo angiogenic effects under hypoxic/ischaemic conditions. Finally, Bråkenhielm et al. [27] described the anti-angiogenic as well as anti-proliferative and pro-apoptotic effects of fAd $(2 \mu \mathrm{g} / \mathrm{ml})$ in the presence of FGF2 (a potent angiogenic factor) in porcine microvascular endothelial cells, interestingly at the optimal time point of $72 \mathrm{~h}$. We, in contrast, performed experiments in HMECs utilising fAd at a maximal concentration of $3 \mu \mathrm{g} / \mathrm{ml}$ and an optimal time point of $24 \mathrm{~h}$. We found that

Fig. 4. The effect of high glucose and CRP on gAd- and fAd-induced functional changes in HMECs. a Proliferation-MTS assay. HMECs were pre-incubated with or without gAd $(3 \mu \mathrm{g} / \mathrm{ml})$ or fAd $(3 \mu \mathrm{g} / \mathrm{ml})$ for $1 \mathrm{~h}$ followed by treatment with or without glucose $(15 \mathrm{mM})$ or CRP $(1 \mu \mathrm{g} / \mathrm{ml})$ for $24 \mathrm{~h}$ and assessed by MTS assay. Results were expressed as percentage of cells in relation to basal (untreated) and represent the mean of triplicates. ${ }^{* *} \mathrm{p}<0.001$; ${ }^{* *} \mathrm{p}<0.01 ; \# \mathrm{p}<0.001 ;+\mathrm{p}<0.001 ; \mathrm{n}=6$ 6/group. $\mathbf{b}$ Endothelial cell migration. HMECs were pre-incubated with or without gAd $(3 \mu \mathrm{g} / \mathrm{ml})$ or fAd $(3 \mu \mathrm{g} / \mathrm{ml})$ for $1 \mathrm{~h}$ followed by treatment with or without glucose $(15 \mathrm{mM})$ or CRP $(1 \mu \mathrm{g} / \mathrm{ml})$ for $24 \mathrm{~h}$. Migrated cells were quantified using a fluorescence plate reader. The migrated cells were expressed as the ratio of the fluorescence compared with the control. Results are means \pm SE of six independent experiments. ${ }^{* * *} \mathrm{p}<0.001 ; \# \mathrm{p}<0.001 ;+\mathrm{p}<0.001 ; \mathrm{n}=6$ 6/group. c Capillary tube formation. HMECs were pre-incubated with or without gAd $(3 \mu \mathrm{g} / \mathrm{ml})$ or fAd $(3 \mu \mathrm{g} / \mathrm{ml})$ for $1 \mathrm{~h}$ followed by treatment with or without glucose $(15 \mathrm{mM})$ or CRP $(1 \mu \mathrm{g} / \mathrm{ml})$ for $24 \mathrm{~h}$. Photos were taken at $24 \mathrm{~h}$ after seeding. The total length of capillary-like tubes was measured and normalised with controls. The values represented are relative to basal. ${ }^{* *} \mathrm{p}<0.001$; $\mathrm{p}<0.001$; $+\mathrm{p}<0.001 ; \mathrm{n}=6$ /group, experiments were performed in triplicates. 

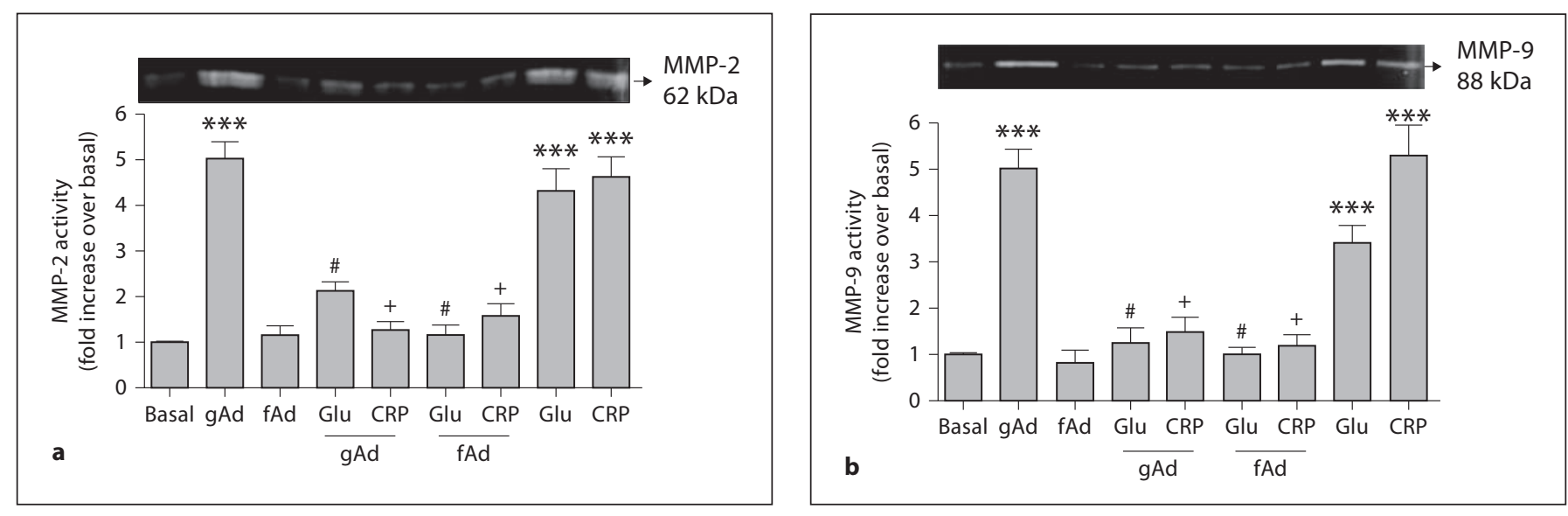

Fig. 5. HMECs were pre-incubated with or without gAd $(3 \mu \mathrm{g} / \mathrm{ml})$ or fAd $(3 \mu \mathrm{g} / \mathrm{ml})$ for $1 \mathrm{~h}$ followed by treatment with or without glucose $(15 \mathrm{mM})$ or CRP $(1 \mu \mathrm{g} / \mathrm{ml})$ for $24 \mathrm{~h}$. a, b Representative zymograms and densitometric analysis of MMP-2 and MMP-9 protein activity in conditioned media for $24 \mathrm{~h}$, respectively. ${ }^{* * *} \mathrm{p}<0.001$; $\# \mathrm{p}<0.001 ;+\mathrm{p}<0.001 ; \mathrm{n}=6$ /group, experiments were performed in triplicates.

fAd was pro-proliferative with no effects on migration and capillary tube formation. Our findings are different to those described above, potentially attributable to the differences in experimental material and methods. In addition, we present novel data showing that endothelial cell proliferation, in vitro migration and angiogenesis were significantly increased by gAd in HMECs.

It is important to note that although in vitro angiogenic assays have been merited as useful reporters in deciphering specific steps, they however lack complex interplay of multiple factors vital for in vivo processes [21, 27]. Taken together, it remains unclear as to whether our observations reflect on balance a beneficial or detrimental effect of adiponectin in vivo. Further studies are needed to clarify this matter.

Adiponectin-mediated effects including angiogenesis in endothelial cells have been reported to mainly involve the AMPK pathway [21]. Studies have indicated that in both normoxia and hypoxia, activation/phosphorylation of AMPK by adiponectin is vital for the initiation of angiogenic phenotype in endothelial cells [21]. However, we report for the first time that gAd-induced endothelial angiogenesis also involves the AMPK pathway. Similar to this, the PI3K/Akt pathway plays an important role in endothelial angiogenesis [28]. Of note, studies have shown the importance of AMPK-Akt cross-talk in mediating pro-angiogenic effects of adiponectin [25]. Concurring with previous reports, we present novel data suggesting the involvement of the AMPK-Akt pathway in gAd-induced endothelial angiogenesis.

Globular Adiponectin and Endothelial Angiogenesis
The link between hyperglycaemia, angiogenesis and microangiopathies as observed in diabetes mellitus has been mentioned above [19]. Of relevance, Hayashi et al. [29] showed that high glucose treatment promotes endothelial cell proliferation, in vitro migration and angiogenesis, consistent with our data. Importantly, we observed that gAd attenuated the effects of high glucose suggesting a possible protective effect of adiponectin in vivo. As alluded to above, coexisting hyperglycaemia and systemic inflammation in diabetes mellitus predisposes to dysregulated angiogenesis and vascular disease, and CRP plays an important role within this context [20]. It is important to note that studies have elucidated the anti-inflammatory effects of CRP in local sites of inflammation by enhancing neutrophil infiltration and polymorphonuclear neutrophil activation. Notwithstanding, the role of CRP can be summarised as having both anti- and pro-inflammatory properties [30].

Our data on the possible beneficial effects of gAd are in keeping with the observations and deductions of Mahadev et al. [31] who showed that gAd decreased VEGFinduced human coronary artery endothelial cell migration. Moreover, our findings of a reduction in CRP and glucose-induced angiogenesis by gAd is in keeping with the report by Hattori et al. [12] which describes marked inhibition of TNF $\alpha$-induced nuclear factor- $\kappa \mathrm{B}$ (a critical mediator of angiogenesis) activation by gAd in endothelial cells. In the same study, the authors also showed the apparent paradox in that gAd on its own significantly induced NFkB activation in endothelial cells [12]. Taken 
together, gAd may therefore cause hyporesponsiveness or desensitization of crucial angiogenic transcription factors that mediate CRP and glucose-induced angiogenesis. This hypothesis was suggested by Hattori et al. [12] in order to explain their apparent paradoxical findings.

Activation of MMP-2 and MMP-9 has been implicated in the development of atherosclerosis and vascular disease [17]. To be precise, it is important to bear in mind that the zymography technique only yields information about MMP levels and not activities. Indeed, although pro-MMPs and MMP-TIMP complexes are not active in biological samples, when analysed by zymography, these molecular forms will be visualized by the degradation of the gelatin substrate. For the proMMPs, this is by artificial activation with SDS and for the MMP-TIMP complexes, this is by the dissociation of the noncovalent complex and visualisation of the free MMP [24]. In addition, MMPs have been implicated in cellular migration. In support of our findings, Mahadev et al. [31] reported that gAd decreased VEGF-induced endothelial cell migration.

With respect to atherosclerosis, it is important to note that the pathological processes involved potentially depend upon other key players, in particular, the recruitment and the infiltration of blood inflammatory cells, specifically, macrophages and $\mathrm{T}$ lymphocytes. In relation to this, a recent report by Mandal et al. [32] demonstrated that both gAd and fAd reduces the sensitivity of macro- phages to activation by pro-inflammatory stimuli, whilst inflammation promotes atherogenesis [20]. It is also important to note that Waki et al. [33] showed that gAd can be generated from fAd by the action of leucocyte elastase secreted by resident macrophages and/or neutrophils. Given these findings, and in conjunction with our observations, we would like to propose a synergistic, potentially protective mechanism of gAd at the initiation site of the atherosclerotic plaque.

A limitation of our study pertains to the observations that the neutralising antibodies, i.e. AdipoR1 and AdipoR2, did not completely neutralise the effects of adiponectin. We did perform experiments with AdipoR1 and AdipoR2 alone but did not find any significant changes (data not shown). Further studies are needed to clarify this point.

In conclusion, we report novel insights into the mechanisms of adiponectin action in combination with proangiogenic molecules (MMPs and VEGF) pertinent to obesity, diabetes and cardiovascular disease. Further in vivo studies are needed to support our novel findings.

\section{Acknowledgements}

We thank the General Charities of the City of Coventry for their support.

\section{References}

1 Eckel RH, Grundy SM, Zimmet PZ: The metabolic syndrome. Lancet 2005;365:14151428.

2 Kershaw EE, Flier JS: Adipose tissue as an endocrine organ. J Clin Endocrinol Metab 2004;89:2548-2556.

-3 Lihn AS, Pedersen SB, Richelsen B: Adiponectin: action, regulation and association to insulin sensitivity. Obes Rev 2005;6:13-21.

-4 Cavusoglu E, Ruwende C, Chopra V, Yanamadala S, Eng C, Clark LT, Pinsky DJ, Marmur JD: Adiponectin is an independent predictor of all-cause mortality, cardiac mortality, and myocardial infarction in patients presenting with chest pain. Eur Heart J 2006; 27:2300-2309.

5 Hada Y, Yamauchi T, Waki H, Tsuchida A, Hara K, Yago H, Miyazaki O, Ebinuma H, Kadowaki T: Selective purification and characterization of adiponectin multimer species from human plasma. Biochem Biophys Res Commun 2007;356:487-493.
-6 Fujimatsu D, Kotooka N, Inoue T, Nishiyama M, Node K: Association between high molecular weight adiponectin levels and metabolic parameters. J Atheroscler Thromb 2009;16:553-559.

7 Baessler A, Schlossbauer S, Stark K, Strack C, Riegger G, Schunkert H, Hengstenberg C, Fischer M: Adiponectin multimeric forms but not total adiponectin levels are associated with myocardial infarction in non-diabetic men. J Atheroscler Thromb 2011;18: 616-627.

8 Hirose H, Yamamoto Y, Seino-Yoshihara Y, Kawabe H, Saito I: Serum high-molecularweight adiponectin as a marker for the evaluation and care of subjects with metabolic syndrome and related disorders. J Atheroscler Thromb 2010;17:1201-1211.

$\checkmark 9$ Kadowaki T, Yamauchi T: Adiponectin and adiponectin receptors. Endocr Rev 2005;26: 439-451.
10 Goldstein BJ, Scalia R, Ma XL, Mahadev K, Wu X, Ouedraogo R: Comment on: Hattori et al. (2007) Globular adiponectin activates nuclear factor- $\mathrm{\kappa} \mathrm{B}$ and activating protein-1 and enhances angiotensin II-induced proliferation in cardiac fibroblasts: Diabetes 56: 804-808. Diabetes 2007;56:e7-e8.

11 Hattori Y, Hattori S, Akimoto K, Nishikimi T, Suzuki K, Matsuoka H, Kasai K: Globular adiponectin activates nuclear factor- $\kappa \mathrm{B}$ and activating protein- 1 and enhances angiotensin II-induced proliferation in cardiac fibroblasts. Diabetes 2007;56:804-808.

$\checkmark 12$ Hattori Y, Hattori S, Kasai K: Globular adiponectin activates nuclear factor- $\kappa \mathrm{B}$ in vascular endothelial cells, which in turn induces expression of proinflammatory and adhesion molecule genes. Diabetes Care 2006;29: 139-141.

13 Baker RG, Hayden MS, Ghosh S: NF-кB, inflammation, and metabolic disease. Cell Metab 2011;13:11-22. 
14 Lau DC, Schillabeer G, Li ZH, Wong KL, Varzaneh FE, Tough SC: Paracrine interactions in adipose tissue development and growth. Int J Obes Relat Metab Disord 1996; 20:S16-S25.

15 Mohamed-Ali V, Pinkney JH, Coppack SW: Adipose tissue as an endocrine and paracrine organ. Int J Obes Relat Metab Disord 1998;22:1145-1158.

16 Creemers EE, Cleutjens JP, Smits JF, Daemen MJ: Matrix metalloproteinase inhibition af ter myocardial infarction: a new approach to prevent heart failure? Circ Res 2001;89:201210.

17 Van den Steen PE, Dubois B, Nelissen I, Rudd PM, Dwek RA, Opdenakker G: Biochemistry and molecular biology of gelatinase B or matrix metalloproteinase-9 (MMP9). Crit Rev Biochem Mol Biol 2002;37:375536.

18 Wang H, Keiser JA: Vascular endothelial growth factor upregulates the expression of matrix metalloproteinases in vascular smooth muscle cells: role of flt-1. Circ Res 1998; $83: 832-840$

19 Crawford TN, Alfaro DV 3rd, Kerrison JB, Jablon EP: Diabetic retinopathy and angiogenesis. Curr Diabetes Rev 2009;5:8-13.

20 Slevin M, Krupinski J: A role for monomeric C-reactive protein in regulation of angiogenesis, endothelial cell inflammation and thrombus formation in cardiovascular/cerebrovascular disease? Histol Histopathol 2009;24:1473-1478.
21 Ouchi N, Kobayashi H, Kihara S, Kumada M, Sato K, Inoue T, Funahashi T, Walsh K: Adiponectin stimulates angiogenesis by promoting cross-talk between AMP-activated protein kinase and Akt signaling in endothelial cells. J Biol Chem 2004;279:1304-1309.

22 Pfaffl MW: A new mathematical model for relative quantification in real-time RT-PCR. Nucleic Acids Res 2001;29:e45.

23 Adya R, Tan BK, Punn A, Chen J, Randeva HS: Visfatin induces human endothelial VEGF and MMP-2/9 production via MAPK and PI3K/Akt signalling pathways: novel insights into visfatin-induced angiogenesis. Cardiovasc Res 2008;78:356-365.

24 Toth M, Fridman R: Metastasis research protocols. Methods Mol Med 2001;57:163-174.

25 Carmeliet P, Jain RK: Angiogenesis in cancer and other diseases. Nature 2000;407:249257.

26 Shibata R, Ouchi N, Kihara S, Sato K, Funahashi T, Walsh K: Adiponectin stimulates angiogenesis in response to tissue ischemia through stimulation of amp-activated protein kinase signaling. J Biol Chem 2004;279: 28670-28674.

27 Bråkenhielm E, Veitonmäki N, Cao R, Kihara S, Matsuzawa Y, Zhivotovsky B, Funahashi T, Cao Y: Adiponectin-induced antiangiogenesis and antitumor activity involve caspase-mediated endothelial cell apoptosis. Proc Natl Acad Sci USA 2004;101:24762481.
28 Ackah E, Yu J, Yu J, Zoellner S, Iwakiri Y, Skurk C, Shibata R, Ouchi N, Easton RM, Galasso G, Birnbaum MJ, Walsh K, Sessa WC: Akt1/protein kinase Balpha is critical for ischemic and VEGF-mediated angiogenesis. J Clin Invest 2005;115:2119-2127.

29 Hayashi JN, Ito H, Kanayasu T, Asuwa N, Morita I, Ishii T, Murota S: Effects of glucose on migration, proliferation and tube formation by vascular endothelial cells. Virchows Arch B Cell Pathol Incl Mol Pathol 1991;60: 245-252.

30 Mortensen RF, Zhong W: Regulation of phagocytic leukocyte activities by C-reactive protein. J Leukoc Biol 2000;67:495-500.

- 31 Mahadev K, Wu X, Donnelly S, Ouedraogo R, Eckhart AD, Goldstein BJ: Adiponectin inhibits vascular endothelial growth factorinduced migration of human coronary artery endothelial cells. Cardiovasc Res 2008; 78:376-384.

32 Mandal P, Pratt BT, Barnes M, McMullen MR, Nagy LE: Molecular mechanism for adiponectin-dependent M2 macrophage polarization: link between the metabolic and innate immune activity of full-length adiponectin. J Biol Chem 2011;286:13460-13469.

33 Waki H, Yamauchi T, Kamon J, Kita S, Ito Y, Hada Y, Uchida S, Tsuchida A, Takekawa S, Kadowaki T: Generation of globular fragment of adiponectin by leukocyte elastase secreted by monocytic cell line THP-1. Endocrinology 2005;146:790-796. 